\title{
Determining Factors That Affecting Financial Performance of Sharia Small Business Bank by Using Ordinal Logistic Regression with Bootstrap Estimation
}

\author{
Muhammad Ridho' ${ }^{1}$, Dodi Devianto ${ }^{2}$ \\ \{dho22.mhd@gmail.com ${ }^{1}$,ddevianto@sci.unand.ac.id ${ }^{2}$ \} \\ Department of Mathematics, Andalas University, Padang, 25163, Indonesia ${ }^{1,2}$
}

\begin{abstract}
The aim of this study is to find out the financial performance's affecting factors of sharia small business bank in Indonesia. Financial performance is the response variable which grouped into three categories, they are bad, medium, and good. Predictor variables involved in this study consisted of 11 numerical data and 1 categorical data. The numerical data are financial capital, productive assets, credit, third party funds, income, capital adequacy ratio, return on assets, return on equity, financing deposit ratio, non performing financing, and operational efficiency. Whereas the categorical data is the location of sharia small business bank ( 1 if it is in rural areas, 2 if it is in the business center, and 3 if it is in a business and urban center). Ordinal logistic regression with a bootstrap estimation is performed to determine the predictor variable that affects the response variable. This study found that two predictor variables affected the response variable significantly, namely return on assets and return on equity with a hit ratio of $96.41 \%$. So that it can be concluded that the model obtained has been able to determine the level of performance of sharia small business bank in Indonesia.
\end{abstract}

Keywords: Bootstrap estimation, Financial performance, Ordinal logistic regression, Sharia small business bank.

\section{Introduction}

Banks have an important role in the economy of a country, one of them as intermediary institutions which channeling public funds into investment asset productive that will boost the real sector productivity, capital accumulation, and aggregate growth. Moreover, the bank's main function is collecting funds from excessive sector and lending it to poor sectors [1] Banks are divided into two type based on it business scale of payment traffic, commercial banks and small business banks. The commercial banks carry out business activities in conventional and sharia principles which in their activities provide services in payment traffic, while small business banks do not provide services in payment traffic. In Indonesia, Small business bank is an official banking institution regulated under Act No.7 of 1992 concerning banking and amended by Act No 10 of 1998 . The existence of a small business bank is to complete people requirement in financial sector with easier provisions than commercial bank.

One type of small business bank is sharia small business bank. Sharia small business bank runs its business activities which do not provide services in payment traffic with sharia principle [1]. Sharia small business bank is an alternative for people who run small and medium businesses and want banks that apply Islamic principles, sharia and its traditions in 
financial transactions. The existence of the sharia small business bank specifically described in the Decree of BI Director No. 32/34/Kep/Dir, on May 12, 1999 concerning commercial banks based on sharia principles, Decree of BI Director No. 32/36/Kep/Dir, on May 12, 1999 and BI Circular Letter No. 32/4/KPPB on May 12, 1999 concerning banks credit people's based on sharia principles and The Indonesian Financial Service Authority regulations No. 3/POJK.03/2016 concerning sharia people's financing banks.

Sharia small business bank as a financial institution must really maintain trust. To maintain that trust, sharia small business bank must maintain the health of its company. The level of sharia small business bank health is the performance and quality of sharia small business bank seen from the important factors that significantly influence the smoothness, sustainability, success of the sharia small business bank. Research on sharia small business bank has been carried out, including Suhel et al [2], Faisol [3], Aziz [4], and Purnamasari and Darmawan [5]. While research on banking performance was carried out by Akhisar et al [6], Kawshala and Panditharathna [7], Abugamea [8], Siddik et al [9], and Nouaili et al[10].

In [2], [3], [4], [5], the researches weremore focused on finding the influence of sharia small business bank on small and medium businesses in the community. Meanwhile in [6], [7], [8], [9], [10], the researches were conducted on the performance of conventional bank. In that previous study, factor that affecting the financial performance of sharia small business bank weren't explained. In this study, the factors that influence the financial performance of sharia small business bank with 12 predictor variables were examined. Financial performance is classified into three groups, namely bad, medium and good. So in this case, an ordinal logistic regression is used to determine the financial performance's affecting factors of the sharia small business bank and to increase the level of accuracy, Bootstrap estimates of standard error are carried out.

\section{Materials}

\subsection{Ordinal Logistic Regression}

Logistic regression method is a data analysis used to find the relationship between response variable (Y) which dichotomous (nominal or ordinal or two-dimensional) or polychotomus (nominal or ordinal scale with three or more categories) scale with one or more continuous or categorical predictor variables $(\mathrm{X})$. In logistic regression, the response variables are not normally distributed, so characteristic function as Fourier-Stieltjes transform is used to explain its characterization because the characteristic function is available for every distribution. The properties of characteristic function for some special distributions have been explained in [11], [12], [13] and its canonical representation of characteristic functions of exponential distribution has been shown in [14]. The probability distribution of ordinal logistic regression response could be characterize by using characteristic function. However, it also exists logit transform as mathematical transformation for characterize specific function, in regression logistic model, logit transformation is performed to give its model.

In essence according to [15], the form of probability function $\pi(x)=E(Y \mid x)$ is used to estimate logistic regression equation as:

$$
\pi(x)=\frac{\exp (\alpha+\beta x)}{1+\exp (\alpha+\beta x)},
$$


where $\alpha$ and $\beta$ are parameters, and $x$ is predictor variables. Then a logit transformation $g(x)$ is conducted to simplify equation as:

$$
g(x)=\ln \left(\frac{\pi(x)}{1-\pi(x)}\right)=\alpha+\beta_{1} x
$$

This transformation is important because $g(x)$ has many of the desirable properties of a linear regression model. The Logit, $g(x)$, is linear in its parameters, may be continuous, and depending on the range of $x$ may range from $-\infty$ to $+\infty$. Specifically, an ordinal logistic regression is a regression analysis used to find and describe the relationship between ordinal scale response variables with more than two categories and a set of continuous or categorical predictor variables. The cumulative function with $\mathrm{r}$ categories response variable of ordinal logistic regression $P(Y \leq r \mid x)$ is defined as:

$$
\mathrm{P}(y \leq r \mid x)=\pi_{r}=\frac{\exp \left(\alpha_{r}+\sum_{k=1}^{t} \beta_{k} x_{k}\right)}{1+\exp \left(\alpha_{r}+\sum_{k=1}^{t} \beta_{k} x_{k}\right)},
$$

where $x$ is the vector value of predictor variables with $t$ categories [16]. If logit transformation is used, the above equation become:

$$
\operatorname{Logit} \mathrm{P}(\mathrm{Y} \leq r \mid x)=\alpha_{r}+\sum_{k=1}^{t} \beta_{k} x_{k}
$$

The opportunity for each $r$ category of the response is obtained based on the cumulative function as:

$$
\mathrm{P}(\mathrm{Y}=r \mid x)=\frac{\exp \left(\alpha_{r}+\sum_{k=1}^{t} \beta_{k} x_{k}\right)}{1+\exp \left(\alpha_{r}+\sum_{k=1}^{t} \beta_{k} x_{k}\right)}-\frac{\exp \left(\alpha_{r-1}+\sum_{k=1}^{t} \beta_{k} x_{k}\right)}{1+\exp \left(\alpha_{r-1}+\sum_{k=1}^{t} \beta_{k} x_{k}\right)},
$$

To estimate theordinal logistic regressionparameters model, the Maximum Likelihood Estimator (MLE) is performed. The MLE method is conducted by maximizing a joint probability density function which is also called the likelihood function.

\subsection{Bootstrap}

The Bootstrap method was first introduced by Efron in 1979 to determine the statistical distribution of unknown samples. The Bootstrap method is a method used to estimate an unknown population distribution where the empirical distribution is obtained from the reshaping process [17]. The Bootstrap method is a method of resampling data for statistical inferencing that is usually used to predict confidence intervals. In addition, it can also be used to predict variety or determine hypotheses.

If $Z=\left(z_{1}, z_{2}, \ldots, z_{n}\right)$ is a random sample of a population then the variable $Z^{*}=\left(z_{1}^{*}\right.$, $\left.z_{2}^{*}, \ldots, z_{m}^{*}\right)$ is a Bootstrap random sample which is a sample obtained from population randomly with returns. The variables $z_{1}^{*}, z_{2}^{*}, \cdots, z_{m}^{*}$ are free and conditionally distributed to $\mathrm{Z}$. 
The * sign indicates that $Z^{*}$ is not a set of data $Z$ but the results of the resample, means the data points $z_{1}^{*}, z_{2}^{*}, \cdots, z_{m}^{*}$ is an $m$-sized random sample with a return from population $m\left(z_{1}, z_{2}, \cdots, z_{n}\right)$.

The Bootstrap method is a nonparametric approach toestimate various statistical quantities such as the mean, standard deviation, and bias of an estimation or toform a confidence interval by following certain algorithms. To analyze and see the level of accuracy of the value of parameter estimates generated using regression logistic, the results obtained need to be done a resampling method, namely Bootstrap resampling method.

\section{Methods}

This Study use the data come from The Indonesian Financial Service Authority. The data is sharia small business bank data in Indonesiain 2017. Two variables are use in this study, they are response variable $(\mathrm{Y})$ and some predictor variable $(\mathrm{X})$. The variable measured response is financial performance of sharia small business bank in Indonesiathat classified into three class, if the financial performance is bad $Y=1$, if the financial performance is middle $Y=2$, if the financial performance is good $\mathrm{Y}=3$.

The Predictor variables consisted of 11 numerical data and 1 categorical data. The numerical data are

1. Financial capital $\left(\mathrm{X}_{1}\right)$ : capital originating from bank owners, consisting of capital paid up by shareholders, reserves and retained earnings.

2. Productive assets $\left(\mathrm{X}_{2}\right)$ : productive assets represent investments in sharia banks both in rupiah and foreign exchange in the form of financing,receivable accounts, sharia securities, placements, participation of equity, income projections, revenue realization, administrative account transactions and bank Indonesia Wadiah certificates.

3. Credit $\left(\mathrm{X}_{3}\right)$ : Credit in sharia banks aims to finance projects or customer needs both urgently and for other consumptive purposes where the funds that are owned by themselves are not enough to overcome the shortcomings.

4. Third party funds $\left(\mathrm{X}_{4}\right)$ : funds from third parties deposited to the bank, which are generally in the form of demand deposits or savings.

5. Income $\left(\mathrm{X}_{5}\right)$ : income obtained from profit sharing systems are in accordance with an upfront agreement between the customer and the sharia small business bank where the revenue sharing is adjusted to the profits or losses of the business carried out by the customer.

6. Capital adequacy ratio $\left(\mathrm{X}_{6}\right)$ : performance ratio of a banks to quantifyabank'scapital adequacy to support assets that contain or produce risks, for example loans given.

7. Return on assets $\left(\mathrm{X}_{7}\right)$ : a ratio of the net income with total assets. It quantify the profit earned per assets and show how well bank management uses the investment resources of bank to generate profits.

8. Return on equity $\left(\mathrm{X}_{8}\right)$ : a ratio of the net income with total equity. It quantify efficiency of a firm at generating profits from every unit of shareholders' equity.

9. Financing deposit ratio $\left(\mathrm{X}_{9}\right)$ : a ratio for measuring the ability to provide funds for withdrawal of depositors or depositors' funds and provision of funds for financing applicants. 
10. Non performing financing $\left(\mathrm{X}_{10}\right)$ : financing which is categorized as substandard, doubtful and loss. It is calculated by comparing the total non-performing financing classified as substandard, doubtful and loss with total financing.

11. Operational efficiency $\left(\mathrm{X}_{11}\right)$ : an effort to find out whether the bank is operating properly, in accordance with the objectives of the establishment and shareholders. The efficiency ratio is measured by comparing operational costs to operating income Whereas the categorical data is the position of sharia small business bank $\left(\mathrm{X}_{12}\right)$ : the geographical location of sharia small business bank which can describe the condition of the bank ( 1 if it is in rural areas, 2 if it is in the business center, and 3 if it is in a business and urban center).

This study perform ordinal logistic regression analysis with bootstrap estimation to obtain significantly expected parameters. The data analysis steps are as follows [18]:

1. Providing descriptive data of financial performance and location of sharia small business bank in Indonesia.

2. Analyzing the best guessed model of ordinal logistic regression by involving all predictor variableswith the following stages:

a. Testing the overall parameter significances of the ordinal logistic regression model simultaneously.

The purpose of this test is to investigate coefficient $\beta$ significance of the predictor variable simultaneously. The hypothesis of this test are:

$H_{0}: \beta_{1}=\beta_{2}=\cdots=\beta_{p}=0$

$H_{1}$ : There is $\beta_{k} \neq 0 ; k=1,2, \ldots, r$

The statistic test used is a G-test or likelihood Ratio Test.

$$
G=-2 \ln \left[\frac{L_{0}}{L_{M}}\right],
$$

where $\mathrm{L}_{0}$ is a likelihood of the model containing constants only and $\mathrm{L}_{\mathrm{M}}$ is the likelihood of the model containing the variables. $\mathrm{H}_{0}$ is rejected at a significant level $\alpha$ if $\mathrm{G}>\chi_{\alpha, \mathrm{df}}^{2}$ with degrees of freedom is $r$ or $\mathrm{p}$-value $<\alpha$. [15].

b. Performing a partial test between predictor variables and response variables.

The analysis is continued to this test if occur rejection $\mathrm{H}_{0}$ in G-test. The aims of this test is to investigate coefficient $\beta$ significance of thepredictor variable partially. The hypothesis are:

$H_{0}: \beta_{k}=0$

$H_{1}: \beta_{k} \neq 0$

This test is performed for each predictor variables $(k=1,2, \ldots, r)$. The statistic test used is a Wald's test.

$$
W_{k}=\frac{\hat{\beta}_{k}}{S E\left(\hat{\beta}_{k}\right)},
$$


where $S E\left(\hat{\beta}_{k}\right)$ is the standard error of the regression coefficient of $k$ and $\hat{\beta}_{k}$ is the expected regression coefficient of $k . \mathrm{H}_{0}$ is rejected at a significant level of $\alpha$ ifW $_{k}>\chi_{\alpha, \mathrm{r}}^{2}$ or $\mathrm{p}$-value $<\alpha$. [15]

3. Performing bootstrap estimate of standard error to increase confidence interval of model

The bootstrap estimate algorithm is according to [17] as

a. Select $B$ independent bootstrap samples $Z^{*}=\left(z_{1}^{*}, z_{2}^{*}, \ldots, z_{B}^{*}\right)$, each consisting of $n$ data values drawn with replacement from $Z$,

b. Evaluate the bootstrap replication corresponding to each bootstrap sample,

$$
\hat{\theta}^{*}(b)=s\left(z_{b}^{*}\right),
$$

where $b=1,2, \ldots, B$,

c. Estimate the standard error $s e_{F}(\theta)$ by the sample standard deviation of the $B$ replications

$$
s \hat{e}_{B}=\left\{\frac{1}{B-1} \sum_{b=1}^{B}\left[\hat{\theta}^{*}(b)-\hat{\theta}^{*}(\cdot)\right]^{2}\right\}^{1 / 2},
$$

where $\hat{\theta}^{*}(\cdot)=B^{-1} \sum_{b=1}^{B} \hat{\theta}^{*}(b)$.

4. Creating the best ordinal logistic regression with Bootstrap estimation models that loading are significant predictor variables.

5. Calculating and interpreting the odds ratio to detect the effect of significant predictor variables on response variable.

6. Conducting classification accuracy of formed model by ordinal logistic regression with Bootstrap estimation.

This purpose of this test is to determine the accuracy of data prediction to know how accurate the model can classifies response variable. The accuracy of the model formed is determined by the hit ratio, which is defined as:

$$
\text { hit ratio }=\frac{\text { number of objects classified precisley }}{\text { number of observation }} \times 100 \%
$$

\section{Results and Discussion}

The ordinal logistic regression analysis with bootstrap estimation were used in this study. The response variable in this study was grouped into three categories, they were bad,medium, or good. There were 167 sharia small business bank in Indonesia which involved in this study. 


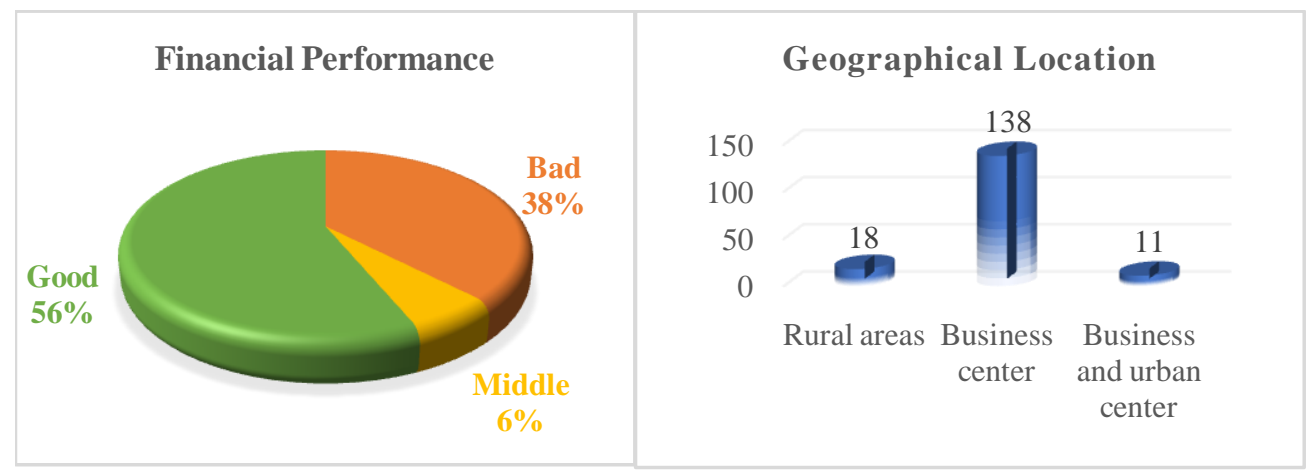

(a)

(b)

Fig. 1.The financial performance and geographical location of sharia small business bank

The financial performance characteristics and location of sharia small business bank in Indonesia could be known through descriptive statistics as follows. Based on fig. 1 (a), the financial performance of majority sharia small business bank in Indonesia was good, only $5.99 \%$ sharia small business bank in Indonesia had bad financial performance. Fig. 1 (b) showed that most of sharia small business bank in Indonesia is in the business center.

The next step was analyzing the best predictedmodel of ordinal logistic regression by involving all predictor variables and testing the overall parameter significances of the ordinal logistic regression model simultaneously using $\mathrm{G}$ statistic test or Likelihood Ratio Test to find out the presence or absence of predictor variables that affect the response variables significantly.

Table 1.Model Fitting Information

\begin{tabular}{lcccc}
\hline Model & $\begin{array}{c}\mathbf{- 2} \text { Log } \\
\text { Likelihood }\end{array}$ & $\begin{array}{c}\text { Chi- } \\
\text { Square }\end{array}$ & Df & Sig. \\
\hline $\begin{array}{l}\text { Intercept Only } \\
\text { Final }\end{array}$ & $\begin{array}{l}287.184 \\
0.000\end{array}$ & 287.184 & 13 & 0.000 \\
\hline
\end{tabular}

Table 1 showed that $\mathrm{p}$-value $<0.05$. So, $\mathrm{H}_{0}$ was rejected. Rejection of $\mathrm{H}_{0}$ meant at least one of prediction variables affects the response variable significantly. Because $\mathrm{H}_{0}$ was rejected, the test analysis was continued to the partial test by using Wald test to determine which predictor variables have a significant effect on the response variable.

Table 2.Parameter Estimates

\begin{tabular}{rcccc}
\hline Variable & Estimate & Wald & Df $_{\text {f }}$ & Sig. \\
\hline Return on assets $\left(\mathrm{X}_{7}\right)$ & 2.547 & 14.695 & 1 & 0.000 \\
Return on equity $\left(\mathrm{X}_{8}\right)$ & 0.169 & 8.521 & 1 & 0.004 \\
\hline
\end{tabular}

Partial Significance Test by Stage $2(\alpha=0,05)$ 
The result Wald test stage 2 was shown in Table 2. The value of all predictor variable significance was less than $\alpha$. With that result, we could conclude that return on assets $\left(\mathrm{X}_{7}\right)$ and return on equity had significant effect on financial performance of sharia small business bank in Indonesia.

The following step was performing Bootstrap estimate of standard error to increase confidence interval of model. The ordinal logistic regression with Bootstrap estimation of standard error result by using $B=300$ Bootstrap samples, each consist of $n=167$ observation show in Table 3:

Table 3.Bootstrap for Parameter Estimates

\begin{tabular}{|c|c|c|c|c|c|c|}
\hline \multirow{3}{*}{ Predictor } & \multirow{3}{*}{$\begin{array}{l}\text { Esti- } \\
\text { mate }\end{array}$} & \multirow{3}{*}{$\begin{array}{c}\text { Std } \\
\text { Error }\end{array}$} & \multicolumn{4}{|c|}{ 95\% Confidence Interval (CI) } \\
\hline & & & \multicolumn{2}{|c|}{$\begin{array}{l}\text { Ordinal Logistic } \\
\text { Regression }\end{array}$} & \multicolumn{2}{|c|}{$\begin{array}{l}\text { Logistic Regression with } \\
\text { Bootstrap Estimate }\end{array}$} \\
\hline & & & Lower & Upper & Lower & Upper \\
\hline & 17 & & 2.276 & & 1.169 & 11.793 \\
\hline & & & 3.792 & + & 1.9 & 18.462 \\
\hline Retur & 2.54 & 2. & 1.245 & 3.849 & 0.621 & 7.435 \\
\hline Return on equity $\left(\mathrm{X}_{8}\right)$ & 0.169 & 0.107 & 0.056 & 0.283 & 0.083 & 0.460 \\
\hline
\end{tabular}

Table 3 showed the increasing of each predictor variables confidence interval. The width of return on assets confidence interval rose from 2.604 to 6.814 and return on equity confidence rose from 0.227 to 0.377 . The best models of ordinal logistic regression with Bootstrap estimation were:

$$
\begin{aligned}
& \operatorname{logit} \pi_{1}(x)=4.179+2.547 x_{7}+0.169 x_{8} \\
& \operatorname{logit} \pi_{2}(x)=6.388+2.547 x_{7}+0.169 x_{8}
\end{aligned}
$$

Furthermore, the value of odds ratio was needed to interpret effect of significant predictor variables on financial performance of sharia small business bank in Indonesia.

Table 4. Value of odds ratio Logistic Regression

\begin{tabular}{rcc}
\hline Variable & Estimate & $\operatorname{Exp~(\beta )}$ \\
\hline Return on assets $\left(\mathrm{X}_{7}\right)$ & 2.547 & 12.769 \\
Return on equity $\left(\mathrm{X}_{8}\right)$ & 0.169 & 1.184 \\
\hline
\end{tabular}

Table 4 showed the odds ratio of return on assets and return on equity were 12.769 and 1.184. Increasing 1 point return on asset affect 12.769 times risk the financial performance of sharia small business bank will be good and increasing 1 point return on equity affect 1.184 times risk the financial performance of sharia small business bank would be good.

The final step was calculating classificationaccuracy of formed model by ordinal logistic regression with Bootstrap estimation. The model classified 64 bad financial performance, 4 middle financial performance, and 94 good financial performance precisely. Details of the classification can be seen in the following table: 
Table 4. The classification accuracy

\begin{tabular}{lcccc}
\hline \multirow{2}{*}{ Observation } & \multicolumn{3}{c}{ Prediction } & Classification \\
& Bad & Middle & Good & accuracy percentage \\
\hline Bad & 63 & 0 & 0 & $100.00 \%$ \\
Middle & 3 & 4 & 3 & $40.00 \%$ \\
Good & 0 & 0 & 94 & $100.00 \%$ \\
Overall percentage & $37.72 \%$ & $2.40 \%$ & $56.29 \%$ & $96.41 \%$ \\
\hline
\end{tabular}

Base on Table 5, the classification accuracy of formed model was $96.41 \%$. It meaned the model can classify $96.41 \%$ financial performance of sharia small business bank in Indonesiaprecisely. Base on that result, the models that formed by using ordinal logistic regression with Bootstrap estimation were good and reliable to predict financial performance of sharia small business bank in Indonesia.

\section{Conclusion}

The characteristics of sharia small business bank in Indonesiashowed that the most financial performance of sharia small business bank was good $(56 \%)$, and almost all of sharia small business bank in Indonesia was in the business center. Base on the result of this study, there were two predictor variable significantly affect the financial performance of sharia small business bank, they were return of assets and return of equity. Whereas the financial capital, productive assets, credit, third party funds, income, capital adequacy ratio, financing deposit ratio, non performing financing,operational efficiency and location of sharia small business bankdid not significantly influence the financial performance of sharia small business bankin Indonesia.

Return of Assets affected the financial performance of sharia small business bank with odds ratio 12.769. This means, increasing 1 point return on asset will affect 12.769 times risk the financial performance of sharia small business bank was good. In other hand, increasing 1 point return of equity give 1.184 time risk the financial performance of sharia small business bank would be good because the odds ratio was 1.184.

The hits ratio of formed model was $96.41 \%$. It meant the model could classify $96.41 \%$ financial performance of sharia small business bank in Indonesiaprecisely. According to the result, theordinal logistic regression with Bootstrap estimation models that had been obtainedwere good and reliable to use as the level of financial performance predictor of sharia small business bank in Indonesia. 


\section{References}

[1]Nazar, M. F. Devianto, D. Maiyastri. Yozza, H.: On the Clustering of Islamic Rural Banks Based on Financial Performance. IEEE Explore: ICAITI 2018. pp. 108-113 (2018)

[2] Suhel. Asngari, I. Mardalena. and Andaiyani, S.:The Economic Scale of Small-Medium Enterprises Financing in Sharia Banking. IJEFI. Vol 8(3). pp. 112-117 (2018)

[3] Faisol.: Islamic Bank Financing and Its Impact on Small Medium Enterprise's Performance. Etikonomi. Vol 16(1) pp. 13-24 (2017)

[4] Aziz, R. M.: Development Of Small Medium Enterprise With External, Internal, and Religiosity Factors In Islamic Banks. Kinerja. Vol 21(1). pp. 17-34 (2017)

[5] Purnamasari, F. Darmawan, A.: Islamic Banking and Empowerment of Small Medium Enterprise. Etikonomi. Vol 16(2). pp. 221-230 (2017)

[6] Akhisar, I. Tunay, K. B. and Tunay, N.: The Effects of Innovations on Bank Performance: The Case of Electronic Banking Services. Procedia - Social and Behavioral Sciences. Vol 195. pp. 369$375(2015)$

[7] Kawshala, H. and Panditharathna, K.: The Factors Effecting on Bank Profitability. IJSRP. Vol 7(2). pp. 212-216 (2017)

[8] Abugamea, G.: Determinants of Banking Sector Profitability: Empirical Evidence from Palestine. JIEF. Vol 4(1). pp. 49-67 (2018)

[9] Siddik, M. N. A. Kabiraj, S. and Joghee, S.: Impacts of Capital Structure on Performance of Banksin a Developing Economy: Evidence from Bangladesh. IJFS. Vol 5(2). pp. 1-18.(2017)

[10] Nouaili, M. Abaoub, E. and Ochi, A.: The Determinants of Banking Performance in Front of Financial Changes: Case of Trade Banks in Tunisia. IJEFI. Vol 5(2). pp. 410-417(2015)

[11] Devianto, D.: The Uniform Continuity of Characteristic Function from Convoluted Exponential Distribution with Stabilizer Constant. AIP Conference Proceedings 1707 American Institute of Physics, New York. pp. 1-5 (2016)

[12] Devianto, D. Maiyastri. Oktasari, L. and Anas, M.: Convolution of Generated Random Variable from Exponential Distribution with Stabilizer Constant. Applied Mathematical Sciences. Vol 9(96). pp. 4781-4789 (2015)

[13] Devianto, D. Oktasari, L and Maiyastri.: Some Properties of Hypo-exponential Distribution with Stabilizer Constant. Applied Mathematical Science. Vol 9(142). pp. $7063-7070$ (2015)

[14] Devianto, D.: On the Class of Infinitely Divisible Exponential Distribution. Journal of Physics: Conf. Series 1097. 012084 (2018)

[15] Hosmer, D. W. and Lemeshow, S.: Applied Logistic Regression.John Wiley \& Sons. Inc, New York (2000)

[16] Agresti, A.: Categorical Data Analysis.John Wiley \& Sons. Inc, New York(1990)

[17] Efron. and Tibshirani, R. J.: an Introduction of the Bootstrap. Chapman and Hall/CRC, New York (1993)

[18] Ridho, M. Devianto, D. Yozza, H. Yanuar, F. and Rahmi, I.: Logistic Regression Analysis with Bootstrap on Determining Factors Affecting Patient Satisfaction Level on Health Services. IEEE Explore: ICAITI 2018. pp. 213-218 (2018) 